\title{
CONTEMPLAÇÃO DAS FORMAS E OS LIMITES DO CONHECIMENTO NO FÉDON E NO BANQUETE ${ }^{1}$
}

Eliane Christina Souza (UFSCar) ${ }^{2}$

souzaech@gmail.com

Resumo: O Fédon e o Banquete são diálogos nos quais a concepção platônica de filosofia não está dissociada de elementos órficos e de construções míticas. Eu proponho que os temas da pré-existência da alma e da imortalidade da alma no Fédon e os mitos contados por Aristófanes e por Diotima no Banquete, examinados em conjunto, fornecem um rico material para a compreensão da natureza e dos limites do conhecimento e da filosofia em Platão. Sugiro ainda, frente a essa interpretação, uma leitura da "súbita visão do belo em si", em Banquete 210e, que leve em conta esses limites. Conhecimento será, a partir dessa leitura, uma busca dinâmica, muito mais do que intuição das formas.

Palavras-chave: conhecimento; formas; dialética; orfismo.

No Fédon, ao mesmo tempo em que Platão mostra o homem como um misto de corpo e alma, ele situa a possibilidade de contato direto com as formas em um plano exterior à vida humana - antes do nascimento e depois da morte. Nesse diálogo, há um forte pessimismo em relação ao conhecimento. Conhecer é conhecer as formas, os objetos puros, e apenas a alma em estado puro pode encontrar esses objetos. $O$ corpo torna-se então um

1 Recebido: 21-09-2014/Aprovado: 06-02-2015/Publicado on-line: 17-02-2015.

2 Eliane Christina Souza é professora adjunta da Universidade Federal de São Carlos, São Carlos, São Paulo, SP, Brasil. 
empecilho ao conhecimento, como diz Sócrates:

A experiência mostra-nos efetivamente que, para conhecermos com clareza um dado objeto, é indispensável que nos libertemos da nossa realidade física e observemos as coisas em si mesmas, pelo simples intermédio da alma. E então sim, ser-nos-á dado, ao que parece, alcançar o alvo das nossas aspirações, essa sabedoria de que nos dizemos amantes - depois de morrermos, já não em vida, como a lógica do argumento pressupõe. Com efeito, se, associados ao corpo, nada podemos conhecer com clareza, das duas uma: ou tal aquisição da sabedoria não existe, ou apenas se concretiza após a morte, precisamente quando (e não antes...) a alma existir em si por si, independentemente do corpo (Fédon 66d-67a). ${ }^{3}$

No plano do Fédon, a ocupação filosófica "consiste em preparar-se para morrer e em estar morto" (64a). Sem um exercício de exame e interpretação do texto, somos tentados a concluir que a morte é uma condição para a contemplação das formas.

Dentro ainda dessa perspectiva, a teoria da reminiscência, apresentada no mesmo diálogo, depende da premissa de que a alma teve contato com as formas antes do nascimento, o que reforça a tese de que o contato direto com o inteligível só ocorre em um plano que está além da mistura corpo-alma. Frente a essa posição, construída em um plano exterior ao da vida humana - a pré-existência e a sobrevivência da alma - o encontro das formas pela alma seria uma condição impossível para nós enquanto um misto corpo e alma. Eu pretendo defender que esse pessimismo de Platão seria real se pensarmos no conhecimento apenas como posse plena das formas.

Como princípio metodológico, delimitarei alguns

3 Utilizei a tradução de M. T. Schiappa de Azevedo (2000) para as citações do Fédon feitas neste artigo. 
conceitos. O termo "conhecimento" será usado para se referir ao contato da alma com as formas. Ao longo do texto, farei a distinção entre "conhecimento pleno", aquele obtido pela alma em condições plenamente favoráveis, e "conhecimento possível", aquele sujeito à precariedade epistêmica em que se encontra a alma quando ligada ao corpo. Enfatizo, no entanto, que, ao tratar do conhecimento em dois níveis, conhecimento pleno e conhecimento possível, não estou pensando em uma ambiguidade do conhecimento. Vou estabelecer uma relação entre eles, sugerindo que o conhecimento pleno é paradigma do conhecimento possível.

No problema apontado em Fédon 66d-67a, é o conhecimento pleno das formas que está sendo considerado por Platão. $\bigcirc$ argumento seria, então: se conhecer é conhecer plenamente, não há conhecimento enquanto a alma estiver unida ao corpo e só há conhecimento após a morte. Certamente, há a possibilidade de interpretar metaforicamente a morte, mas não é esse o percurso que vou seguir. Vou argumentar que 1. há, nos diálogos, e mais especificamente nos diálogos eleitos para este estudo, a ocorrência do que eu chamo de conhecimento possível; 2. nos dois diálogos em questão, Platão utiliza o conhecimento pleno em condições associadas ao orfismo e aos mistérios, inserindo-o em uma esfera que está além da vida humana ou que exige iniciação; 3. a relação entre conhecimento possível e conhecimento pleno mostra o papel da filosofia para Platão nesses diálogos.

Começo pelo primeiro tópico. Se levarmos em conta que, nos diálogos, a conclusão da dialética tem um aspecto negativo, parece que a posse do conhecimento não resulta 
de um percurso que seja de fato um método. Apesar de todo o esforço investigativo de Platão, a maioria dos diálogos nos deixa como que carentes do encontro das formas e, aporeticamente, longe do conhecimento pleno. $\mathrm{O}$ escopo da questão é imenso, eu reconheço, mas proponho reduzir meu material de trabalho e pensar, inicialmente, a relação entre conhecimento pleno e conhecimento possível a partir da aproximação entre filosofia e amor no Banquete. ${ }^{4}$ Dois mitos criados por Platão irão me auxiliar nisso: o mito do nascimento de Eros, narrado por Sócrates/Diotima, e o mito contado por Aristófanes.

O sentido erótico da filosofia, exposto pela sacerdotisa Diotima na narrativa feita por Sócrates (201e-202a), parte do seguinte argumento: há algo entre o belo e o feio, assim como há a opinião correta entre a sabedoria e a ignorância. ${ }^{5}$ O amor não é belo nem feio, nem bom nem mau; é um intermediário entre esses opostos. A natureza desse intermediário é explicada por uma bela história (203b204a). Eros não é um deus, é um daimon que nasceu no aniversário de Afrodite, sendo filho da mortal Carência (Penia) e do deus Recurso (Poros). Por ter sido gerado no aniversário de Afrodite, Eros é por natureza amante do belo, e por ser filho da falta e da saída, sua natureza guarda características da mãe e do pai. Devido à natureza da mãe Carência, ele é sem sabedoria e sempre pobre. Ao contrário de delicado e belo, como a maioria das pessoas julga, Eros é duro, seco, descalço e desabrigado, convivendo sempre com

\footnotetext{
4 Em um trabalho publicado anteriormente (SOUZA 2006), comecei a trabalhar esse tema, que no presente artigo é mais bem desenvolvido.

5 Não é o caso de pensar que, no Banquete, haveria uma equivalência entre filosofia e opinião correta. Opinião correta é usada, nessa passagem, como exemplo de um dos intermediários entre sabedoria plena e ignorância total.
} 
a necessidade. Do pai Recurso, ele herdou a coragem e a riqueza. Ele é insidioso com o que é belo e bom, corajoso, decidido e enérgico. É ávido de sabedoria, um caçador sempre a tecer maquinações cheias de artimanhas. Quando enriquece, ele germina e vive, mas carência faz com que lhe escape tudo o que consegue. Recurso, então, o faz ressuscitar. Assim, a natureza de Eros não é mortal nem imortal, nem pobre nem rica, nem sábia nem ignorante. Eros é um intermediário, já que sua natureza dupla o impede de se identificar com a falta ou com a plenitude. Por isso mesmo, Eros é filósofo (204b).

Segundo as palavras de Diotima (204a), nenhum deus filosofa ou deseja ser sábio, pois já o é. A filosofia, então, se distingue da posse da sabedoria. Filosofia é desejo de sabedoria e quem já a possui não filosofa. Tampouco os ignorantes filosofam nem desejam ser sábios, pois não deseja quem não imagina ser deficiente naquilo que não pensa the ser preciso. Os que filosofam são os que estão entre esses dois extremos, sabedoria e ignorância. Aqui, se esclarece o elo entre filosofia e amor. Uma das coisas mais belas é a sabedoria, e o amor é amor pelo belo, de modo que o amor é filósofo. E a causa dessa condição é a sua origem, filho de um pai sábio e rico e de uma mãe que não é sábia e que é pobre.

A comparação entre amor e filosofia permite pensar no sentido da filosofia em Platão. Ela não seria posse plena de sabedoria. Os filósofos, amantes do conhecimento, não são sábios, são carentes de sabedoria. Essa carência se revela no desejo de sabedoria da personagem Sócrates, cuja postura aponta para o dinamismo investigativo da filosofia. $O$ filósofo, desejoso de saber, reconhece que não tem a posse plena de um conhecimento, mas tem o recurso para buscá- 
lo. Porém, tal qual Eros, o que ele consegue lhe escapa.

Por que, então, desejar aquilo que nunca alcançaremos? Por que não nos contentamos em trabalhar com nossos julgamentos sobre os dados dos sentidos? O mito contado por Diotima permite dizer que, se há filosofia, ela não é apenas carência. Dando um passo para além do mito, em direção ao caráter geral da filosofia como dialética na obra platônica, a filosofia não é apenas o reconhecimento de que opinião não é conhecimento. Esse reconhecimento seria o primeiro passo da dialética, o impulso inicial para a busca daquilo que não se sabe. A partir daí, o recurso nos permite continuar a busca dialética. A natureza carente da filosofia indica que ela não é posse plena da sabedoria, mas recurso para uma aproximação do conteúdo das formas. Na busca dialética, a carência indicaria, por exemplo, a dificuldade em saber se a definição alcançada pelo acordo entre os interlocutores é um conhecimento ou uma opinião, enquanto o recurso seria, por exemplo, a possibilidade de reconhecer as contradições contidas em uma opinião, na tentativa de saber se ela é ou não verdadeira. $O$ aspecto negativo da dialética não significa uma prevalência da carência sobre o recurso, senão a característica da natureza dupla do conhecimento - desejo de saber e condições para alcançar o conhecimento. Essas condições, no entanto, sempre encontram um limite, que está na própria incapacidade humana em atingir plenamente o inteligível.

O mito do nascimento de Eros tem seu contraponto no mito que o comediante Aristófanes havia apresentado anteriormente (189a-193d). O discurso de Aristófanes é o quarto no diálogo, ocupando seu centro, o que marca sua importância estratégica. Para Aristófanes, amor é o remédio que consegue curar humanidade. Eros não é o deus mais 
antigo, o mais útil ou o mais novo, como disseram os oradores anteriores. Ele é "o deus mais amigo do homem, protetor e médico desses males, de cuja cura dependeria sem dúvida a maior felicidade para o gênero humano" (189d). ${ }^{6}$ A seguir, ele propõe iniciar os ouvintes no poder do amor. Antes de falar da ação do amor, no entanto, é preciso aprender sobre a natureza humana (antropine physis), pois, sem isso, não compreenderíamos a natureza de Eros. A apresentação da natureza humana e do papel de Eros é feita através da seguinte fábula. Os homens eram originariamente completos, possuíam forma esférica, o que os tornava fortes, e se dividiam em três gêneros - macho, fêmea e andrógino. Ao pretenderem destronar Zeus, foram castigados e separados em duas partes e Apolo foi encarregado de costura-los do lado cortado. Essa é a marca de um sofrimento na natureza humana. Ao cortar os homens em dois, Zeus os preserva, porém os enfraquece.

Desde que a natureza dos homens se mutilou em duas partes, passa a ansiar por sua própria metade. Quando a encontra, cada metade se atira respectivamente sobre a outra - macho sobre macho, fêmea sobre fêmea, macho sobre fêmea -, agarrando-a sem soltá-la, e assim pereciam as partes por inanição. Essas metades mutiladas procriavam depositando o esperma na terra onde as fêmeas deixavam os ovos, fertilizando-os. Zeus encontra uma solução para a inanição da completude, virando os órgãos genitais para frente. A geração passa a se processar um no outro, se se tratar de macho e fêmea. Se for um homem com outro homem, a solução de Zeus garante ao menos "saciedade e repouso para retomarem as demais ocupações" (191c). 
No mito de Aristófanes, o homem traz em si a marca da incompletude. Cada ser humano é um anthropon symbolon. O symbolon remete a uma antiga prática de cortar um objeto em duas partes, as quais um hóspede e um hospedeiro guardam e transmitem a seus filhos; essas duas partes aproximadas fazem com que os portadores se lembrem de suas relações de hospitalidade. ${ }^{7}$ Eros aparece como o restaurador da natureza humana, "em sua tentativa de fazer um só de dois" (191d). Quando alguém se encontra com a sua metade, o amor é extraordinário, a ponto de não quererem se separar. Seu desejo é o de unirem-se e tornarem-se um só, resgatando sua antiga natureza completa (holon). As metades assim completadas voltariam a ser fortes e não se separariam mais. $\mathrm{O}$ amor é a força que move os seres fragmentados a buscar sua parte mutilada, o desejo da completude e o empenho em restabelecê-la (192e).

Temos, na fala de Aristófanes, a novidade da associação entre amor e desejo (epithymia). Esse desejo aparece em um estado bruto, como movimento de retorno à condição original. Mesmo com a operação de Zeus, que introduz a saciedade no contato sexual, o amor não deixa de ser desejo de unir-se e confundir-se com o amado, pois o que realmente os homens visam não é o sexo, mas uma proximidade tal que simboliza a unidade para sempre perdida. Platão, ao mesmo tempo em que coloca na fala de Aristófanes um elemento erótico extremamente importante, aponta um paradoxo no anseio humano de completude. $\mathrm{O}$ amor de que fala Aristófanes é um retrato da natureza humana e Eros realiza nosso desejo de sermos

7 Segundo o Dictionnaire Grec-Français A. Bailly. 
completos. Essa completude, no entanto, equivaleria a uma morte do próprio desejo, uma vez que o bem procurado foi encontrado e, com isso, cessa todo o movimento de busca e toda ação.

No contraste entre o mito narrado por Aristófanes e o mito narrado por Diotima e na associação entre filosofia e amor, Platão está dizendo qual é sua escolha de projeto filosófico. Diotima fala do amor filósofo, um retrato de Sócrates - carente de beleza, descalço, sem lar, um intermediário entre a sabedoria e a ignorância. $\mathrm{O}$ discurso de Diotima mostra o aspecto construtivo do desejo ao fazer de Eros um caçador cheio de artimanhas. Eros não se conforma em encontrar o desejado, pois sabe que a carência vai empobrecê-lo tão logo ele enriqueça. Por isso, sua atuação é contínua. Por isso, não é papel da filosofia, enquanto amor, a contemplação estática das formas.

Platão, nas palavras de Diotima, faz uma crítica ao amor possessivo defendido por Aristófanes:

E de fato corre um dito, continuou ela, segundo o qual são os que procuram a sua metade os que amam; o que eu digo porém é que não é nem da metade o amor, nem do todo; pelo menos, meu amigo, se não se encontra este em bom estado, pois até os seus pés e mãos querem os homens cortar, se lhes parece que o que é seu está ruim. Não é com efeito o que é seu, penso, que cada um estima, a não ser que se chame o bem de próprio e de seu, e o mal de alheio; pois nada mais há que amem os homens senão o bem (205e-206a).

O que o amor procura não é a completude, mas o bem. Em toda a fala de Diotima, o bem está intimamente associado ao belo. O amor é amor de ter sempre consigo o bem/belo (206a). Há, portanto, um esforço, uma ação (ergon) naquilo que se chama amor (206b). O amor é um parto em beleza, tanto no corpo quanto na alma (tokos en kaloi kai kata to soma kai kata ten psychen - 206c). O desejo passa a ser 
configurado assim:

... é algo de perpétuo e imortal para um mortal, a geração. E é a imortalidade que, com o bem, necessariamente se deseja, pelo que foi admitido, se é que o amor é amor de sempre ter consigo o bem (207a). ${ }^{8}$

Eros deseja o belo e o bom. O desejo de gerar no bem/belo é comum a todos os homens, pois todos querem ter o que é bom para si e se esforçam para manter o bem junto de si. $\mathrm{O}$ amor do corpo tem em vista a geração de belos filhos; o amor da alma, a geração de belas obras e, dentre elas, a filosofia, queproduz belos discursos que conduzem à sabedoria.

A filosofia, enquanto Eros, é desejo que não encontra completude, é um desejo que não cessa com o encontro do seu objeto, mas é essencialmente busca. É inegável que, para Platão, conhecimento significa buscar as formas e trabalhar apenas com o princípio de tudo (República 511b). Também é inegável que a dialética platônica é uma investigação que procura esclarecer as relações entre as formas, sem recurso aos sensíveis (Sofista 253 c-d), e que seu horizonte é a verdade. Porém, se por um lado, na perspectiva platônica, o conhecimento nos é necessário e fundamental, por outro lado, ele se mostra insuficiente em algumas situações nos diálogos. Como vemos, por exemplo, em República 505a, não temos um conhecimento adequado do bem. Esse conhecimento imperfeito é o que eu chamo de "conhecimento possível". Pode-se pensar nessa imperfeição como resultado da própria natureza humana,

8 Embora eu não me proponha a fazer isso aqui, não seria difícil pensar na ação ética e política do filósofo desenhado por Diotima Embora eu não me proponha a fazer isso aqui, não seria difícil pensar na ação ética e política do filósofo desenhado por Diotima. 
um misto de corpo e alma, e também se pode pensá-la como uma maneira de mostrar o caráter dinâmico da filosofia. Sócrates não tem um conhecimento adequado do bem, mas tem recurso para produzir um logos sobre o bem a partir da imagem do sol.

Há também outro aspecto do dinamismo da busca filosófica. Se a filosofia fosse um conhecimento acabado e objetivo, a busca dialética teria como foco uma verdade universal, mas o que vemos nos diálogos é a atuação de Sócrates dirigida de modo específico aos diversos interlocutores e aos diversos contextos em que as questões aparecem. 9

É nesse misto de carência e recurso que vemos que a obra platônica é constituída de diálogos cujo drama equivale ao próprio drama da alma humana. A alma tem uma natureza capaz de contemplar as formas, representada pelo recurso, mas que está unida a um corpo que dificulta esse acesso, dificuldade representada pela carência. A filosofia não é nem só recurso nem apenas carência, mas é carência ao mesmo tempo que recurso. Por possuir recurso para buscar a sabedoria, a filosofia diferencia-se da ignorância, mas, por ser carente, não lhe cabe a sabedoria completa.

No Banquete, a posse do saber é um atributo que não pertence aos homens - só os deuses são sábios. No Fédon, Platão também situa a posse plena do conhecimento fora da vida humana - antes do nascimento ou após a morte. Ou seja, o conhecimento pleno está para além da mistura corpo e alma no Fédon e para além da possibilidade

9 Vários estudos mostram essa atuação de Sócrates, entre eles os de Casertano (2012) e Bolzani (2008). 
humana na passagem referida do Banquete. A filosofia, no entanto, não se dá na alma sem o corpo - isto seria a morte -, nem é julgamento sobre as sensações corpóreas sem conhecimento - isto nos levaria à sofística. A filosofia é a busca da verdade pela alma, apesar do corpo; ou melhor, é a busca da verdade que parte do pensamento sobre o sensível, uma busca que faz com que a doxa que obtemos a partir das percepções seja submetida ao logos até que possamos nos aproximar do modelo inteligível.

A reflexão, a busca dialética, não seria um método que traz garantia da apreensão do conteúdo pleno das formas. Nossa natureza mista de corpo e alma, de carência e recurso, irá sempre revelar sua falta enquanto dificuldade para distinguir opinião verdadeira de episteme. Quando, através da dialética, nos aproximamos de uma verdade - aí está a ação do recurso -, essa verdade deverá ser colocada à prova - o que corresponde à ação da carência. Esse limite humano, resultado da mistura alma-corpo, nos impede de atingir plenamente o inteligível. Mas essa mesma falta que mostra nossos limites nos faz desejantes de sabedoria, o que mantém viva a busca filosófica.

A figura de Sócrates nos diálogos não apresenta uma filosofia acabada e, portanto, finita. Tampouco seu horizonte está para além dos limites humanos. A filosofia que ele mostra é uma busca que, quando encontra seu objeto, ao mesmo tempo o perde, pois ele é novamente colocado como questão. É uma busca incessante, mas, nem por isso, infrutífera. A filosofia, como Eros, é pobre, descalça e desabrigada, mas, ao mesmo tempo, é corajosa, caçadora e ardilosa. É com esta imagem que Platão traça Sócrates, aquele que sabe que não sabe, mas é movido pelo desejo de saber. 
Quero notar, entretanto, que essa interpretação do sentido da filosofia para Platão encontra um problema dentro do próprio diálogo escolhido como objeto desta abordagem. No Banquete, a passagem entre 210a-211d descreve o encontro da alma com a forma do belo. Esse encontro é frequentemente interpretado como uma intuição independente dos sentidos e da mediação dos logoi, que corresponderia ao verdadeiro conhecimento. Sem a pretensão de entrar na árdua discussão sobre conhecimento intuitivo e conhecimento proposicional em Platão, quero mostrar que a leitura proposta, segundo a qual o contraste entre os mitos de Aristófanes e de Diotima se refere ao conhecimento possível e aos limites da filosofia, não pode ser pensada em consonância com a interpretação da "súbita visão do belo" como conhecimento pleno ou como intuição.

A escala ascendente do amor em direção ao belo (Banquete 209e-212a), no entanto, permite uma interpretação que não colide com o que vem sendo sustentado até aqui. Pretendo indicar que a ascensão amorosa no Banquete tem um caráter religioso semelhante às teses da preexistência da alma e da sobrevivência da alma no Fédon e, tal como acontece nesse diálogo, cumpre duas funções: mostrar os limites do conhecimento e remeter ao logos como via de acesso ao conhecimento possível.

A filosofia como uma preparação para a morte (Fédon 64a), a virtude como um tipo de purificação (Fédon 69c) e a descida simbólica ao Hades (Fédon 69c-d), em aproximação ao mito de Perséfone, representam rituais que colocam a filosofia como uma iniciação aos Mistérios:

[...] como dizem os entendidos nos Mistérios, "muitos são os portadores de tirso, mas poucos os bacantes": ora, estes últimos, 
quer-me parecer que não são outros senão os que se consagram, no verdadeiro sentido da palavra, à filosofia (Fédon 69c-d).

Ao colocar o contato da alma com as formas nessa perspectiva religiosa, Platão mostra que formas só são plenamente acessíveis em uma condição fora do humano. O plano órfico seria, nessa seção do Fédon, uma maneira de lidar com o inteligível, indicando, ao mesmo tempo, sua inacessibilidade e sua possibilidade de acessibilidade.

O contato com o inteligível, logo a seguir, é tratado através do argumento da reminiscência (72e-77c), que contém também fortes elementos órficos, representados pela premissa de que a alma existiu antes do corpo. Ao mesmo tempo, a reminiscência é definida em uma sequência que começa com a aisthesis e tem sua continuidade na ennoia (concepção) do igual em si, estabelecendo uma valorização epistêmica da percepção (aisthesis). Para que haja reminiscência, é necessário ter como ponto de partida a percepção, uma vez que ela mostra uma contradição nos fenômenos que leva a buscar as formas. No exemplo, é a visão de coisas ao mesmo tempo iguais e desiguais que evocam a forma do igual, ou seja, é a percepção de uma deficiência que provoca a lembrança.

Segundo a teoria platônica da reminiscência, há um conhecimento prévio das realidades absolutas que torna possível todos os outros conhecimentos. O termo 'prévio', aqui, se refere não necessariamente a uma anterioridade temporal, mas a uma anterioridade lógica. $\mathrm{O}$ conhecimento da forma é prévio em relação à apreensão do sensível porque é sua condição de possibilidade. Esse conhecimento primitivo tem sua origem em alguma condição superior à vida sensível e temporal, isto é, livre do devir, mas ele não nos é diretamente acessível. No entanto, já que existe, entre 
os seres sensíveis e os inteligíveis, uma relação imagemmodelo, é possível apreender as formas, ou, em outros termos, reconhecê-las, a partir dos seres sensíveis que são suas imagens. Tal reconhecimento, a reminiscência, não ocorre espontaneamente como resultado direto da experiência. Ele seria resultado de uma reflexão sobre as contradições que os atributos dos seres sensíveis manifestam - igualdades que são desiguais, unidades que são múltiplas.

A saída para o pessimismo cognitivo do Fédon, sem que se lance mão da presença órfica, é dada na sessão final do diálogo. $\mathrm{O}$ trabalho com os logoi aparece como uma possibilidade para o conhecimento:

[...] uma vez desiludido da observação dos seres (ta onta), achei por bem acautelar-me, não viesse a acontecer-me a mim o mesmo que àqueles que contemplam e observam o sol em momentos de eclipse: é sabido que alguns chegam a perder a vista, se não for através da água ou de qualquer outro meio que mirem a sua imagem (eikona). $\mathrm{E}$, com pensamentos mais ou menos deste teor, receei ficar irremediavelmente cego de espírito, caso persistisse em fixar os olhos nas coisas, em tentar tocar-lhes diretamente com meus cinco sentidos. Pensei então que o melhor que tinha a fazer era refugiarme do lado das ideias ( $\log o i)$ e, atraves delas, inquirir da verdade dos seres. (Fédon 99d-e).

A explicação dessa exposição de Sócrates termina assim:

Ora, vê se pensas também como eu quanto ao que daqui se infere. Por mim, parece-me efetivamente que, se alguma coisa bela existe além do belo em si, a única e exclusiva razão de assim ser é o fato de participar (metechei) desse mesmo belo. (Fédon 100c)

O argumento, longe de apresentar uma solução definitiva, lança a participação como hipótese. $\mathrm{O}$ trabalho com o logos, embora não seja chamado de "dialética", mostra semelhanças evidentes com o processo que conduz o 
raciocínio na direção das formas em diálogos como República. Cabe notar também que, tal como ocorre em várias passagens da busca dialética platônica, o trabalho com o logos nessa passagem do Fédon depende do acordo do interlocutor. ${ }^{10} \mathrm{O}$ trabalho com o logos, que tem como objeto a participação das formas, equivaleria ao conhecimento possível.

Se esse exame paralelo entre Fédon e Banquete for plausível, eu sugiro que o encontro da alma com o belo tem, possivelmente, um caráter iniciático tão forte quanto o encontro com as formas pela alma desencarnada. $\mathrm{O}$ aspecto iniciático da ascensão amorosa no Banquete marca um limite, ao mesmo tempo em que traz a condição de possibilidade para conhecimento.

Em 206b, Diotima apresenta a filosofia como iniciação à imortalidade e, após dizer que o amor mortal tem em vista a eternidade através da geração de belos filhos e que o amor da alma tem em vista a eternidade através da geração de belas obras e belos discursos que conduzem à sabedoria, Platão coloca, ainda na boca de Diotima, as seguintes palavras:

São esses então os casos de amor em que talvez, ó Sócrates, também tu pudesses ser iniciado (muetheies); mas, quanto à sua perfeita contemplação, em vista da qual é que esses graus existem, quando se procede corretamente, não sei se serias capaz (Banquete 209e).

Os graus da iniciação amorosa são: 1. do amor por um único corpo ao amor por muitos corpos; 2. do amor pela beleza física ao amor pela beleza das almas e das leis; 3 . o amor pela beleza da totalidade da sabedoria; 4. da beleza de 
todos os estudos para a beleza de um único estudo; 5. a súbita visão (exaiphnes katopsetai) do belo em si (210e). Os cinco estágios são confirmados no sumário em 211c-d:

Eis, com efeito, em que consiste o proceder corretamente nos caminhos do amor ou por outro se deixar conduzir: em começar do que aqui é belo e, em vista daquele belo, subir sempre, como que servindo-se de degraus, de um só para dois e de dois para todos os belos corpo, e dos belos corpos para os belos ofícios, e dos ofícios para as belas ciências até que das ciências acabe naquela ciência, que de nada mais é senão daquele próprio belo, e conheça enfim o que em si é belo (kai gno auto teleuton ho esti kalon).

Diotima insiste em que devemos começar pelos objetos físicos, e por um corpo em particular, e que devemos ir além dele, para escapar à perspectiva restrita de um só ponto de vista e ir em direção do que é universalmente belo. Nos quatro primeiros estágios, se produzem belos e magníficos discursos. $\bigcirc$ último estágio será, então, dedicado apenas à contemplação do belo, como um contato não-sensível e não-discursivo?

A forma do belo, na escala ascendente do Banquete, é alcançada pela alma fora de suas relações com outras formas. Esse isolamento da forma, tanto em relação às outras formas quanto em relação ao logos, se tomado como um conhecimento pleno, como uma atividade noética imediata e acabada, parece um pouco distante do projeto filosófico de Platão em outros diálogos. Arrisco dizer que se distancia do projeto do próprio Banquete, se levamos em conta o sentido da filosofia a partir do mito do nascimento de Eros. Sugiro que a contemplação (theasthai), na ascensão erótica do Banquete, considerando seu caráter iniciático, pode ser lida da mesma maneira que o encontro das formas pela alma desencarnada no Fédon. É uma maneira de mostrar o papel da alma frente ao que é invisível mas que 
pode ser visível de algum modo.

O que Platão chama de contemplação da beleza não precisa ser entendido apenas como o encontro passivo e completo de uma forma. Ao longo da fala de Diotima, há uma transformação de Eros do desejo de possuir coisas belas ao desejo de criá-las no belo. A ascensão do filósofo é um esforço contínuo para entender a beleza dos objetos de Eros e é inseparável da produção dos mais belos e bons logoi, embora o termo 'logos' não esteja explícito na passagem que trata da contemplação. Esse movimento, essa constante busca das questões que ainda não estão respondidas, é essencial para a filosofia. $\bigcirc$ filósofo, que faz um parto no belo, diz Diotima, não produz imagens da virtude (tiktein ouk eidola aretes), mas produz a virtude real (alethe) (212a). A produção da virtude real pode significar tanto a produção de ações boas e virtuosas quanto a produção e a articulação dos logoi que aproximam a alma do conhecimento da virtude. A contemplação do belo seria um exemplo de conhecimento possível muito mais do que de conhecimento pleno. Contemplar plenamente o belo é algo que apenas um iniciado, alguém em condições especiais pode conseguir. Há, porém, uma contemplação possível do belo, enquanto produção de belas ações e articulação de belos logoi em vista do belo em si.

Quero, como conclusão, ter o cuidado de não associar o horizonte mítico-religioso de Platão a um ato estranho à filosofia. $\mathrm{O}$ que eu sugiro é que o plano iniciático no qual a apreensão das formas é colocada nas passagens indicadas do Fédon e do Banquete mostra um limite da filosofia, a inatingibilidade da contemplação das realidades puras. Isso não significa que o conhecimento filosófico, para Platão, fica comprometido. A posse plena do conhecimento como 
encontro das formas pela alma desencarnada ou como súbita visão da forma do belo seria o paradigma do conhecimento perfeito, mas esse não é o conhecimento humano. Ele representa o modelo ideal de conhecimento. A alma, em sua mistura com o corpo, não atingirá plenamente esse conhecimento. Cabe a ela o conhecimento possível, a investigação filosófica. Talvez por isso Diotima não esteja certa de que Sócrates seja capaz de alcançar o mais alto dos Mistérios. Ele, no entanto, não deixará de buscá-los.

Abstract: The Phaedo and the Symposium are dialogues in which Plato's conception of philosophy is not dissociated of orphic elements and mythical constructions. I propose that the themes of the pre-existence of the soul and the immortality of the soul in the Phaedo and myths told by Aristophanes and Diotima in the Symposium, examined together, provide rich material for understanding the nature and limits of knowledge and philosophy in Plato. I also suggest, before this interpretation, a reading of the "sudden vision of beauty in itself," in Symposium 210e, which takes into account these limits. Knowledge is, from this reading, a dynamic search, much more than intuition of the forms.

Keywords: knowledge; forms; dialectic; orphism.

\section{REFERENNCIAS}

ADLURI, V. Initiation into the Mysteries: The experience of the irrational in Plato. Mouseion. Series III, Vol. 6, p. 407-423, 2006.

BERNABÉ, A. Platão e o Orfismo. Trad. de D. Xavier. São Paulo: Annablume, 2011.

BOSTOCK, D. Plato's Phaedo. Oxford: Clarendon Press, 1986.

BOLZANI FILHO, R. Platão trágico e antitrágico. Letras Clássicas. n-12, p. 151-168, 2008. 
Casertano, G. Definição, dialética e lógos: apontamentos para um estudo sobre a dialética em Platão. In: MIGLIORI, M. (org). Platão e Aristóteles - Dialética e Lógica. São Paulo: Loyola, 2012. p. 55-71.

Casertano, G. O bem e a linha. In: XAVIER, D. G. e CORNELLI, G. (org), A República de Platão: outros olhares. São Paulo, Loyola, 2011. p. 285-298.

CORRIGAN, K. \& E. G. Plato's Dialectic at Play: Argument, Structure, and Myth in Plato's Symposium. Pennsylvania: Pennsylvania State University Press, 2004.

FRONTEROTTA, F. La visione dell'idea del bello: Conoscenza intuitiva e conoscenza proposizionale nel Simposio (e nella Repubblica). Perspectiva Filosófica. Volume II, n 36, p. 23-42, julho a dezembro 2011.

GONZALEZ, F. 'All of a Sudden': Discontinuities and the Limits of Philosophy in Plato's Symposium. Perspectiva Filosófica. Volume II, no 36 , p. 23-42, julho a dezembro 2011, p. 43-70.

MORAVCSIK, J. M. E. Reason and Eros in the Ascent Passage of the Symposium. In: ANTON J. P. \& KUSTAS A. P. G. L., Essays in Ancient Greek Philosophy I, Albany: State University of New York Press, 1972. p. 285-302.

NEHAMAS, A. Only in the contemplation of beauty is human life worth living. Plato, Symposium 211d. European Journal of Philosophy. Volume 15, Issue 1, p. 1-18, 04/2007.

PLATÃO. Banquete. Tradução de J. C. Souza. São Paulo: Difel, 2006. 
PLATÃO. Fédon. Tradução de M. T. Schiappa de Azevedo. Brasília: Editora da UNB, 2000.

PLATON. Oeuvres Complètes. Traduit par A. Diès, A. Croiset et alli. Paris: Les Belles Lettres, 1993.

SCOTT, G. A. \& WELTON, W. A. Erotic Wisdom: Philosophy and Intermediacy in Plato's Symposium. New York: State University of New York Press, 2009.

SOUZA, E. C. A filosofia carente. Boletim do CPA. Campinas, v. 20/21, p. 23-33, 2006.

TRABATTONI, F. Il sapere del filosofo. In: VEGETTI, M. (ed.) Platone. La Repubblica. Vol.V. Napoli: Bibliopolis, 2003. p. 151-186.

TRABATTONI, F. Platão. Tradução de R. Quinália. São Paulo: Annablume, 2010. 